is fully ripe not only saves grain that might be lost by shattering, but also helps to reduce the rat population in the fields. When less scattered rice is left for rats to pick up, the rodents fail to get their usual supply of vitamins necessary for large litters, and their increase is smaller. In many places of the Far East old storage houses are being cleaned and made rodent-proof, and new stores are being built. An oldfashioned method of rodent control is being revived in Malaya. The rice godowns are first surrounded by snakeproof fencing. Then an expedition is made into the nearby jungle to capture pythons, which are given a home under the floor of the godown. There is no rat problem in the godowns policed by pythons.

Efforts have been made by governments to improve handling facilities at the rice mills; but they have not met with complete success. For example, a rice mill in Bangkok has recently completed a modern rice-storage plant on the Chao Phya River. The most up-to-date mechanical process has been installed to unload the paddy by sucking up the grain from the sampans and elevating it into the bins. But many local boatmen have refused to use the modern storage elevator. They are afraid that the boat and all its contents, including the boatman's family, will be drawn into the pipe with the paddy. They prefer to use the conventional and less economical method of unloading by coolies, each coolie carrying two baskets on a wooden yoke balanced across his shoulders. The moddern elevator can unload a large sampan with six or eight tons of paddy in less than thirty minutes ; but it takes several hours by the more conventional hand method.

Another bottleneck in the rice situation is the unsettled political and economic situation in many areas, such as China, Indo-China and Burma, where rice production has decreased below that of 1949 and 1948. Lack of adequate police protection from roving guerrilla bands has forced rice farmers to abandon temporarily fields some distance from their villages, thus reducing the area under rice. Guerrillas have also caused complete failure of normal transportation systems to bring the paddy to the mill. In Burma, before the War, it was possible to bring paddy down the Irrawaddy River from the rice-growing area north of Rangoon in large barges carrying $1,000-2,000$ tons each. Guerrillas and bandits have now made this practice practically impossible. Armed convoys of ten or fifteen trucks must now be organised, each carrying approximately 1.5 tons, to transport rice to the mills. The convoy is often halted by armed men and must pay tribute before passing on. In spite of these difficulties, Burma exported $1,200,000$ tons of rice in 1949 to feed people in the Far East ; but costs of delivery have increased many times above pre-war.

One way to make the most of rice supplies, of course, is to see to it that the nutrients of rice are preserved and consumed. In an area where the protein foods are scarce, and where beriberi is a common nutritional disease, the Food and Agriculture Organisation has found that milling may cause a loss of 15 per cent of the protein present in husked rice, and as high as 75 per cent of the thiamine, which is essential to prevent beriberi. Rice supplies are frequently so dirty that they require excessive washing in the home. Through excessive washing and improper cooking, 10 per cent of the protein, $10-15$ per cent of the calorie value, and 80 per cent of the thiamine may be lost.

The Food and Agriculture Organisation has long recommended under-milling practices, parboiling of rice before milling, educational campaigns for better cooking of rice, enrichment at the mill, and more diversified diets for the rice-consuming people of the world, which represents more than half of the total. The nutritive value of rice strains needs research and continuing consideration in breeding programmes for better varieties.

Dietary changes are taking place in the Far Eastern rice area, including a trend in some sections away from rice as a staple food. This trend has been caused by a scarcity of rice and the economics of the situation. Rice prices have increased six or eight times since before the War, whereas wheat prices have only doubled in the same period. Two tons of wheat can usually be bought for the same price as one ton of rice. A new generation is growing up without the usual dependence on rice. Some authorities believe a number of areas may never again go back completely to rice as a staple cereal.

\section{PHYSICO-CHEMICAL PROPERTIES OF NUCLEIC ACIDS}

A

SYMPOSIUM on the physico-chemical properties and behaviour of nucleic acids, organised by the Colloid and Biophysics Committee of the Faraday Society, was held at the Institut Français, London, on May 12. The choice of this subject is indicative of the recent growth of interest in the chemistry of nucleic acids. Although nucleic acids were first isolated nearly eighty years ago, it is only in the past decade that some knowledge of the size, shape and structure of these macromolecules has been obtained. The topics dealt with in the symposium were representative of the research in progress in Great Britain and on the Continent of Europe. Prof. E. K. Rideal (London) presided during the morning, and during the afternoon Prof. R. Signer (Berne) and Prof. V. Desreux (Liège) shared the duties of chairman. Abstracts of the papers submitted will be published in the Transactions of the Fraraday Society.

Ribonucleic acid preparations which have been studied by various physico-chemical techniques, and which have been used in biological studies, are very heterogeneous, and the preparation of homogeneous fractions by electrophoretic and ultracentrifuge methods have proved difficult. By fractionation of samples prepared from yeast, $B$. coli, pancreas and chicken embryo, using the different solubilities in aqueous alcohol, Prof. Desreux has isolated ribonucleic acid fractions which from solubility data appear homogeneous. Two main fractions of ribonucleic acid were isolated in each case, having molecular weights of 50,000 and 5,000. The particles of the high molecular-weight fraction were asymmetric, having an axial ratio of $9: 1$. The physico-chemical characteristics, for example, diffusion and sedimentation constants, axial ratio, electrometric titration curve and solubility, indicate that the fractions of ribonucleic acid prepared from yeast and $B$. coli are similar.

The electrometric titration of deoxypentose nucleic acids was discussed by Mr. D. J. Cosgrove (Nottingham) and Dr. A. R. Peacocke (Birmingham). Mr. Cosgrove described the anomalous titration eurve obtained with a sample of deoxypentose nucleic acid which had been prepared by keeping all solutions at or very close to $p H$. Addition of acid or alkali to 
a solution of the sodium salt at $p H$ does not at first bring about the titration of groups in the $p H$ range 5-11; the titration of groups is delayed until a critical $p H$ region is reac'sed, where the liberation of ionized groups occurs rapidly. The back-titration curves, either from $p \mathrm{H} 12$ or 2.5 , are more normal and agree with the calculated curve based on a knowledge of the dissociation constants of the purinepyrimidine amino groups and $-\mathrm{NH}-\mathrm{CO}-$ ('hydroxyl') groups. The reaction which occurs on the addition of acid or alkali is irreversible, and a similar change occurs on heating the solution of the sodium salt of the deoxypentose nucleic acid. The anomalous titration curve is not affected by the method of preparation of the nucleic acid so long as treatment with acid or alkali is avoided; this is particularly interesting in that two very different methods of separating the nucleic acid from the protein were employed, namely, the chloroform gel method and the salt precipitation method, and thus confirms the findings of Prof. Signer (see below). Similar titration curves have been obtained for acids prepared from calf thymus, herring sperm and from lamb thymus, and it would appear that the anomalous titration curve is characteristic of all deoxypentose nucleic acids. The anomalous titration curve has been explained by postulating the existence of hydrogen bonds between the $-\mathrm{NH}-\mathrm{CO}-$ groups and the $-\mathrm{NH}_{2}$ groups of different purine and pyrimidine rings in the acids as initially prepared. Dr. Peacocke pointed out that the titration curves obtained by him did not quite agree with those of Mr. Cosgrove, in that the back-titration curve from $p \mathbf{H} 12.5$ was not identical with that from $p \mathbf{H} 2 \cdot 5$. The effect of ultrasonic vibration is to produce degradation of the nucleic acid and, like heat and alkaline treatment, to destroy the anomaly in the titration curve.

In the preparation of high molecular-weight deoxypentose nucleic acid, which was described by Prof. $R$. Signer (Berne), the most important precaution is the inhibition of nuclease activity by cooling to $-80^{\circ} \mathrm{C}$. and by the addition of enzyme inhibitors. Prof. Signer also considers it is essential that the nucleoprotein prepared by extraction with 10 per cent sodium chloride solution be repeatedly purified by precipitation, which is achieved by diluting the solution to $1 \cdot 0$ per cent sodium chloride concentration. The molecular weight and viscosity are not affected by the method of separating the nucleic acid and protein, and either the chloroform-gel or the saltprecipitation method may be employed.

An X-ray study of nucleosides and nucleotides has been made by Dr. S, Furberg (Oslo), and was described by Dr. C. H. Carlisle (London). In cytidine the pyrimidine ring is flat, and the ribose ring, for which there is some evidence that it is not planar, lies in a plane perpendicular to that of the pyrimidine. The structure of cytidylic acid is similar, the phosphoric acid being attached to the $3^{\prime}$ position. The study of the structure of nucleic acids has been carried to a stage where it is possible to postulate, on the basis of packing considerations, two arrangements of the nucleotides. One is a straight-chain structure, the nucleotides being arranged in the form of a zigzag, and the other is a spiral structure. Both structures give a fibre spacing in agreement with that observed previously by Prof. W. T. Astbury.

Dr. D. P. Riley (London) gave wn account of the wide-angle X-ray scattering of solutions of the sodium salt of deoxypentose nucleic acid. At low concentrations, only small-angle scattering is observed but at concentrations greater than 5 per cent there are three distinct regions of refraction at 3-10, 20-50 and $50-200 \mathrm{~A}$. At these rather high concentrations, the solutions are really liquid crystals and exhibit marked domain birefringence. The higher spacings vary as $1 / 5 C$, where $C$ is the volume concentration. These data have been interpreted as indicating that the molecules are cylinders of diameter $46 \mathrm{~A}$.. presumably formed by the coiling of the long chain; on dilution the separation between the cylinders increases. The scattering which is observed with nucleoproteins is somewhat different, the larger spacing being absent.

The problems involved in the determination of the molecular weight of nucleic acids by means of the ultracentrifuge were considered by Dr. A. G. Ogston (Oxford). Marked molecular interaction makes it necessary to extrapolate the sedimentation and diffusion constants to zero concentration. The sedimentation constant $S$ may be satisfactorily extrapolated as $1 / S$ against concentration to give a limiting value for the deoxypentose nucleic acid of calf thymus of $13.2 \times 10^{-13}$. The extrapolation of the diffusion constant is performed with the aid of Flory's theory of the entropy of solutions of large particles to give a value of $0.55-0.70 \times 10^{-7}$. The molecular weight then lies between 1.0 and $1.3 \times$ $10^{5}$, and the axial ratio is $140-170$, which is in reasonable agreement with the value of 190 obtained from viscosity measurements when using a high rate of shear.

Light-scattering measurements on dilute solutions of the sodium salt of deoxypentose nucleic acid were described by Dr. G. Oster (London). The molecular weights of the samples studied varied from 0.51 to $3.23 \times 10^{6}$ according to care of preparation, and were independent of concentration of electrolyte up to $0.2 M$. Measurement of the angular scattering with incident and scattered light under polarizing conditions indicates that the nucleic acid particles are rods with strong negative birefringence and are not random chains. Viscosity measurements on the same samples are in accord with the light-scattering results if it be assumed that the diameter of the particle is approximately $40 \mathrm{~A}$. This value, which is in agreement with the $\mathrm{X}$-ray scattering results of Dr. Riley, has been confirmed by some preliminary electron micrographs (made by Mr. H. L. Nixon), which show that the nucleic acid particles are fibres with a diameter of approximately $50 \mathrm{~A}$.

Dr. S. Jungner (Stockholm) then described the dielectric properties of deoxypentose nucleic acids. The molecular weight of a thread-like molecule with a permanent dipole moment such as deoxypentose nucleic acid may be calculated from the anomalous dispersion of the dielectric constant. In nucleic acid the individual dipoles are oriented across the long axis of the molecule, so that the dipole moment is proportional to the number of nucleotides and therefore to the molecular weight. The values of the molecular weight obtained in studies on dilute solutions are somewhat lower than those obtained by ultra. centrifuge and light-scattering methods, being in the range $1-6 \times 10^{5}$. Also in contrast with the lightscattering results is the observation from dielectric measurements that the particle weight decreases considerably to a value of 35,000 on the addition of electrolyte. These results are interpreted as indicating a reversible disaggregation rather than the coiling process hitherto suggested as the cause of the decrease in viscosity. The addition of magnesium ions appears 
to have a specific effect in bringing about irreversible changes: on precipitation of the nucleic acid with ethyl alcohol in the presence of magnesium ions, large artificial aggregates are formed.

The behaviour of nucleic acids as polymeric electrolytes was discussed by Dr. D. O. Jordan (Nottingham). The nucleic acid polymer contains both strong and weak electrolytic groups, and the presence of the former and the ionization of the latter affect the viscosity of its solutions and the shape of the titration curve. The viscosity of deoxypentose nucleic acid shows considerable structural character, and the viscosity at low pressures is high. The addition of electrolyte reduces the viscosity considerably, as has also been described for simpler systems, for example, polymethacrylic acid and poly N-nbutyl-4-vinyl pyridonium bromide. This process is explained by the repulsion of the charged groups $\left(\mathrm{PO}^{-}\right.$at $p \mathrm{H}$ 7) maintaining a stretched polymer in aqueous solution. The addition of electrolyte reduces this repulsion, thereby permitting the molecule to coil, thus producing a more symmetrical molecule and reducing the viscosity, the structural character of the viscosity and the streaming birefringence. The analogy between nucleic acids and synthetic polymeric electrolytes cannot be carried too far, since the number of gegenions absorbed into the micelle is large, as indicated by the value of $550 e$ for the charge per molecule in a solution of ionic strength 0.005 , compared with the calculated value of $2664 e$ for a molecule of molecular weight $8.2 \times 10^{5}$. The presence of the gegenions in the micelle will reduce tine number of effective ionized groups, thereby decreasing the repulsion. The dissociation constants are all found to be weaker than in the monomer. Calculation of the $p \mathrm{~K}$ values at different degrees of ionization for the - NH - CO - dissociations shows a decrease in acid strength as ionization increases; the initial value, however, is weaker than that for the nucleoside. This is presumably due to the presence of the $\mathrm{PO}^{-}$groups. The case of the amino groups is more complicated, the field effect produced by the ionization to $\mathrm{NH}_{3}+$ and by the $\mathrm{PO}^{-}$groups operating in opposite senses.

The degradation of deoxypentose nucleic acids by chemical agents was outlined by Dr. J. A. V. Butler (London). The extent of degradation was followed by measurement of viscosity. The action of $\mathrm{X}$-rays had been shown previously to produce degradation during the irradiation and to give an after-effect in which the degradation continued after the source of radiation had been removed. This after-effect has now been shown not to occur in the absence of oxygen and is probably due to the presence of hydrogen peroxide or $\mathrm{HO}_{2}$ radicals in solution. A similar degradation to that produced by X-rays may be obtained from the action of free hydroxyl radicals formed by the irradiation of hydrogen peroxide by ultra-violet light or by the reaction between the ferrous ion and hydrogen peroxide. Similar degradation is observed by the action of sulphur and nitrogen mustards. Ultracentrifugal analysis of the degradation products, by Dr. B. E. Conway and Dr. L. Gilbert (London), has shown that there is a considerable reduction of the molecular weight from $1 \times 10^{6}$ to about $1 \times 10^{5}$, the products being very heterogeneous and containing some low molecular-weight fractions which diffuse very rapidly. These degradations, however, are not nearly so extensive as that produced hy the action of deoxyribonuclease.

D. O. JORDAN

\section{BRITISH LEATHER MANUFAC- TURERS' RESEARCH ASSOCIATION}

\author{
By DR. HENRY PHILLIPS \\ Director
}

TCORPORATED in 1920 and starting with a modest income, the British Leather Manufacturers' Research Association at first rented laboratory space for its small staff in London at the Battersea Polytechnic, the Lister Institute and the Imperial College of Science and Technology. Largely the child of the heavy leather industry, the Association rejected the late Prof. A. Smithells's suggestion that its headquarters should be near the Leather Industries Department of the University of Leeds, then guided by Prof. H. R. Procter, because the tanneries in the Leeds area mainly produce light leathers ; although scientifically similar, there are fundamental differences between the processes of these two sides of the industry. The Association therefore went to London, where it was near the headquarters of the United Tanners' Federation and the Federation of Light Leather Tanners and Dressers, and also the heavy and light leather industries of Bermondsey.

When Dr. Dorothy Jordan Lloyd succeeded the first director, Dr. R. H. (later Sir Robert) Pickard, the staff was gathered together in laboratories up in St. Thomas Street, London, S.E.1. Industrial support for the Association grew steadily, and by 1938 sufficient reserve funds had accumulated to enable more commodious laboratories to be furnished in Nelson Square, Blackfriars Road, London. These laboratories were carefully planned and provided a compact and convenient research centre. Occupied in 1939, they were not destined to survive very long, for they were badly damaged in the bombing of 1940, fortunately at night during the absence of the staff. Space for about half the staff was improvised on the ground floor and in the basement of the bombed building; the remainder found accommodation first at Rothamsted Experimental Station and the Leathersellers' Technical College, and later in a large laboratory above the Royal Institute of Chemistry.

At the end of the War, permission to reinstate the laboratories in Nelson Square was refused. The industry was reluctant to move the Association from Bermondsey ; but, after the death of Dr. Jordan Lloyd in 1946, a review of the circumstances suggested that the prospects of rehousing within the London area were slight. The Association therefore decided that a search should be made to find a country mansion suitable for conversion and within a radius of twenty miles of London. The final choice fell on Milton Park, a large Georgian-type mansion, situated in thirteen and a half acres of grounds and within walking distance of Egham Station. After a public inquiry, opposition to the conversion was withdrawn. Fairly extensive repairs and modifications to drainage and supply services had to be made; but in a little more than a year the conversion was completed, and the new laboratories were opened by H.R.H. the Duchess of Kent on May 22.

The leather industry is often referred to as a traditional industry, with the implication that the tanner is conservative and reluctant to adopt new mothods. This is a superficial view: industries remain traditional so long as scientific knowledge lags behind empirical knowledge. Fibre science and 